\title{
E-HRM and Outsourcing For Arabic Countries and Large Organisations
}

\author{
Ghassan Kbar (PhD) \\ Riyadh Techno Valley, King Saud University \\ Riyadh, Kingdom of Saudi Arabia \\ gkbar@ksu.edu.sa \\ gahkbar@yahoo.com
}

\author{
Wathiq Mansoor (PhD) \\ American University in Dubai \\ Dubai, United Arab Emirate \\ wmansoor@aud.edu
}

\begin{abstract}
Organization processes put lots of emphasis on improving efficiency and effectiveness where outsourcing and offshoring non-core as well as core activities play essential role in achieving these objectives. Adopting outsourcing and offshoring at organizations has many benefits including saving cost using low-wage labor markets, allowing companies to focus on their core business which can lead to increase efficiency and competitiveness, as well as enabling organizations to have the right expertise that can't be found in-house and transferring unpredictable risks to contractors. On the other hand there will be issues associated with outsourcing which need to be taken care of and can include monitoring quality, security protection and legal issues, culture and social issue which resulted in backlash of jobs going overseas, and business time convenient. Electronic HRM (E-HRM) becomes widely used in organizations for online recruiting, online advertisement of jobs, online storage of employees CV, and creating a competitive advantage by managing people and complex information in the global workplace easily. This results in speeding up the recruitment times and eventually reduces the transaction costs as well as helping organizations to search and access resumes for potential employees. HR outsourcing and e-HRM can be used together to form the HR architecture which achieve better organizational efficiency at low cost. The HR outsourcing/offshoring and e-HRM are extremely needed for organizations at Arabic countries to better utilize the expertise at developed and affordable countries in order to speed up the HR process and especially in recruiting the right professional peoples from overseas.
\end{abstract}

Keywords-component; Outsourcing; e-HRM; offshoring; Governance; Risk Management;

\section{INTRODUCTION}

Outsourcing for organizations implies the use external third-party providers to provide services for them which are usually done in-house. Organizational strategy for outsourcing of Human Resources related work has increased significantly over the last decade (Cooke, Shen \& McBride 2005). Offshoring is also a kind of outsourcing where work can be done remotely at different countries and usually at low cost (Farrell, Diana, Martha \& Rosenfeld 2006). Digital economy and fast global market contributed to the fast acceptance of offshoring of certain products and services (Peter, Cathy, Ross \& Amanda 2012). There are various motives for adopting outsourcing, which include improving the effectiveness and efficiency at the organization, saving of cost, utilizing the right skills externally, releasing of manager's time to focus on more strategic issues, relying on temporary contractors to do irregular demands, transferring unpredictable risk to external contractors, and improving the service quality (Cooke, Shen \& McBride 2005). Improving the performance of HR functions can be one of the main motives for large companies that have extensive HR functions, where this can be done by outsourcing of HR functions in order to respond to organizational changes including the innovations in processes and products (Alewell, Hauff, Thommes \& Weiland 2009). Outsourcing decision would also be impacted by structural and situational factors such as, the firm size and the demand of personnel services in a firm (Kock, Wallo, Nilsson \& Höglund 2012).

On the other hand outsourcing can have drawbacks which include the lack of building skills needed to sustain product leadership and building 
long-term competitiveness, and the possibility for loss of quality due to disruption of services (Cooke, Shen \& McBride 2005). The lack for empirical results that measures the effectiveness of outsourcing might contribute to the hesitation for adopting outsourcing. This can be related to organizational control as well as not having the expected quality which become barrier for supporting offshoring and outsourcing (Farrell, Diana, Martha \& Rosenfeld 2006). The security and legal issues that might lead to infringing of information would also destruct organization from adopting outsourcing (Schwartz 2005).

Human Resources Intermediaries (HRI) is a kind of service providers which offer HR services to public and private organizations (Alewell, Hauff, Thommes \& Weiland 2009). Compared to HR consultants who focus on specific HR applications, HRI can offer larger solutions which include the entire HR domain since it usually has unique networks that are valuable to clients. Moreover, outsourcing would require complex interactions between HR service providers and in-house HR professionals as well as employees of the organization in order to execute the different transactional HR functions. Electronic HRM (EHRM) that contains major HRM components such as e-recruitment, e-learning, and e-compensation can assist in making effective interactions at low cost, better quality, and fast response (Dhamija 2012). E-HRM that relies on IT and virtual organizations can be used to build and maintain competitive advantage for organizations and have significant impact on innovation (Liang-Hung 2011; Mahmud, Billah \& Chowdhury 2012; Parry 2011), and can be used to improve service delivery as well as assisting in delivering the company's business strategy (Parry 2011). HR outsourcing and e-HRM can be used together to form the HR architecture as suggested by Kanter 2004.

\section{DISCUSSION AND LEARING FROM BEST \\ Practices}

HR tasks include many activities which can be grouped as noncore such as transactional or administrational, or core such as organizational strategy which cover policy, direction, guideline, good practices and culture. There are different performance factors that would affect the efficiency of executing the HR functions. These factors are related to the goals of the HR entity, the in-house $\mathrm{HR}$ team and its capability, the size of the firm and its strategic direction, and the process management and how it can affect the decision. There are various HR goals associated with different firms including large companies, which can be related to some or all of the following: reducing the overall cost of handling HR functions, deliver service on time and with right quality, maintain sustainable skills to offer essential services, having enough time for manager to focus on strategic issue, reducing the risk associated with security and avoiding conflict, maintaining the competitive advantage of firms, using the right technology that offers flexibility and fast response time, and having a good strategy according to budget. Senior HR management should assess the Firm's performance factors to support outsourcing, as well as considering the impact of outsourcing on employees to determine the HR functions that can be outsourced, and what part can be supported using e-HRM solution. Analysis has done by (Alewell, Hauff, Thommes \& Weiland 2009; Cooke, Shen \& McBride 2005) and found that transaction services or other administrative work such as payroll, recruitment, training, career support, outplacement, and form submission can be outsourced since it mainly leads to efficient work at low cost (Alewell, Hauff, Thommes \& Weiland 2009), while other critical strategic activities such as HR strategy, policy and regulation should be done in-house in order to reduce the risk of insecurity and losing the competitive advantages, as well as maintaining the right skills needed for the long term plan of the firm and its sustainability (Cooke, Shen \& McBride 2005).

There can be various impacts associated with the execution of outsourcing on different people including HR professionals, employees affected by the services, line managers, and agent who offer the services (Cooke, Shen \& McBride 2005). Job loss and interaction issues between organizations and service providers should be considered and monitored by the in-house HR staff (Pickard 2000b). Line managers who know the business should work closely with HR manager to make the decision of what to be outsourced and how to monitor the performance of service providers (Cooke, Shen \& McBride 2005). Interaction between in-house employees and service providers can have a significant impact on the workplace where it should be handled with care. Furthermore, conflict might arise between internal HR personnel and service providers who might use standardized tools and not addressing the organization unique requirements (Alewell, Hauff, Thommes \& Weiland 2009).

Outsourcing of certain non-core HR functions at larger organizations is encouraged because of the expected high quality of services that can be offered by high qualified outsourcing agents at relatively low cost, but at the same time these organizations would also be interested in maintaining the firm's competitive advantage by allocating a high budget to attract the right skills and expertise to develop the long term strategic direction in-house. The existing professional HRI who have the right networks and professional capabilities to offer most of the HR functions at high quality, would encourage large organizations to consider outsourcing of its noncore HR functions (Kock, Wallo, Nilsson \& Höglund 2012). Therefore, a mixture of in-house for core HR function and outsourcing of noncore HR function 
seems to be optimal for many situations and would be advisable for large companies (Cooke, Shen, \& McBride 2005).

Figure 1 illustrates the relationship between HR service provider such as HRI, organization that includes in-house HR professionals, other management including inline manager, and employees, and the interaction tools that can rely on technology and e-HRM solution. The in-house HR professional team interacts with the inline managers to get their help and support for making the right decision of what HR functions can be outsourced and monitored, interacts with the firm's employees to manage its transactional services, and interacts with $\mathrm{HRI}$ or external outsourcing service companies to deliver and monitor the HR services done by them. Since HRI playing the role of mediating interaction between employer and employees, choosing the right $\mathrm{HRI}$ for large organization should be based on service offered by HRI at low cost, improving the performance of the HR function with high quality, sharing of skills to improve the in-house knowledge and capacity through training, maintaining the long term competitiveness, and reduce capacity for handling organizational changes (Alewell, Hauff, Thommes \& Weiland 2009).

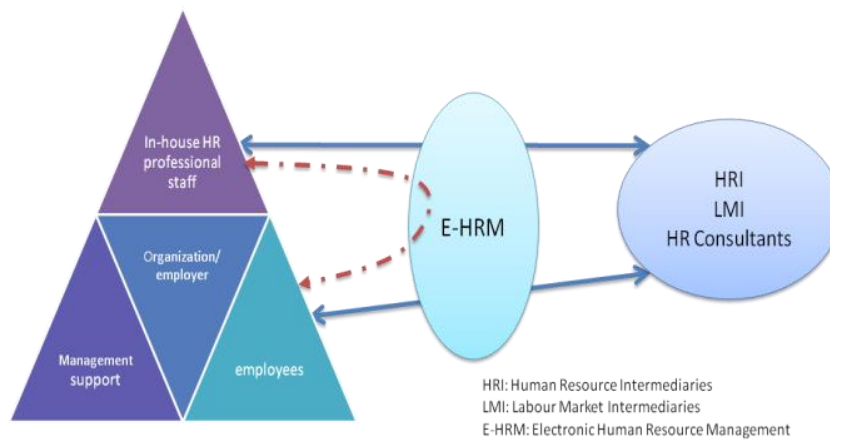

Figure1: Outsourcing of HR functions using HRI services and e-HRM technology.

The e-HRM has essential role in providing effective e-communication between the in-house $\mathrm{HR}$ professionals or HRI and employees such as elearning and e-recruitment as well as outplacement and career support, and between the HRI and the in-house HR professional team for fast process and cost reduction (Bondarouk \& Ruël 2009; Furtmueller, Wilderom \& Tate 2011; Parry \& Tyson 2011). However, supporting of outsourcing would require $\mathrm{HR}$ managers to analyze its impacts and how to reduce the risk associated with it. For example, managing the interaction between HRI and in-house HR professionals should be done properly by having the right skills with general knowledge for the in-house team and using the right technology solution such as e-HRM to optimize the execution and benefit from the services offered by e-HRM (Peter, Cathy, Ross \& Amanda 2012, chapter 4). There are many extra benefits for supporting e-HRM Social Networks that can also be used for interaction between organizations or HR service providers to communicate with employees, but organizations should introduce new ecommunication policies and practices to avoid misusing this technology by employees (Peter, Cathy, Ross \& Amanda 2012, chapter 4; HR Focus 2010; Jie 2005)

Outsourcing and e-HRM at Arabic countries would be encouraged as most of these countries lack the right expertise at home to do the work and they can rely on the e-HRM technologies that can be outsourced to the proper recruiting agents to assist them in attracting the right talents to be employed. This will achieve a high quality of services that can be offered by high qualified outsourcing agents at relatively low cost, but at the same time Arabic organizations should consider maintaining the firm's competitive advantage by allocating enough budgets to attract the right skills and expertise to train the in-house managers for developing the long term strategic direction

\section{ROLE OF LEADERSHIP AND GOVERNANCE IN E-HRM AND OUTSOURCING}

Leaders play essential role in establishing the right rules for corporate or organizational governance by considering the government regulations, and affecting the manager's behaviors to ensure the right execution according to the established organizational governance. Their role would include the ability to solve problems, developing governance with common good, and adopting the right leader behavioral model that have effects on all stakeholders, on self, and on the society. Leaders should assist the HR manager in establishing the right governance for supporting outsourcing (Debnath, Chandra \& Kenji 2011), eHRM and virtual team by analyzing the organizational long strategic direction for employment in order to achieve sustainability and employing the right talents as well as benefiting from the existing technology to support HR management (HRM). The improvement of Digital Technologies in 21st Century had many impacts of the competitive dynamics of organizations which led to having high complexity in identifying the right strategy to exploit the differences with other competitors. This makes firms depend on others where outsourcing and strategic alliances become the preferable options for successful business. Hence, formulating the right strategy for organizations should consider the organizational capabilities and resources to develop the competitive advantage, where outsourcing and e-HRM can complement the organizational task execution for non-core businesses while focusing on in-house tasks execution for core businesses. Leaders are motivated by their beliefs that are rooted to national culture, ethic, society, humanity and religion. Good influencing organizational HR governance would develop regulations and policies 
to support the economic growth through: good collaboration-based strategies, trustful relationship through democratization, support of globalization and outsourcing. HR manager should develop the right governance to support working in virtual team to improve the task's performance that can involve activities such as organizational citizenship behaviors, supporting colleagues, and following the rules that assist in maintaining good organization climate and networks.

\section{CONCLUSION}

Outsourcing has many benefits for organizations that can include saving transaction cost, improving effectiveness and efficiency. However, outsourcing of HR activities should be based on certain functions that are not critical and strategic for organizations in order to protect the confidentiality and preserve the firm's competitive advantages. The lack of empirical results for measuring the effectiveness might discourage some organizations for not adopting outsourcing however the benefit that can be offered by $\mathrm{HRI}$ and the lack of HR expertise at organizations would attract them to adopt it in the future. The eHRM plays important role in the outsourcing process since it makes communication among all parties more efficient and adaptable with fast response at real time. Outsourcing of non-core services is encouraged for big companies as well as Arabic countries in order to benefit from high quality of services that can be offered by high qualified outsourcing agents at relatively low cost.

\section{REFERENCES}

Alewell, D., Hauff, S., Thommes, K. and Weiland, K.'(2009), 'Triggers of HR outsourcing decisions - an empirical analysis of German firms', International Journal of Human Resource Management, Volume 20, Number 7, Pages 1599-1617.

Bondarouk, T.V. and Ruël, H.J.M. (2009), 'Electronic human resource management: challenges in the digital era', International Journal of Human Resource Management, vol. 20 , no. 3 , pp. $505-514$.

Dhamija, P. (2012), 'E- recruitment: a roadmap towards e-human resource management', Researchers World: Journal of Arts, Science \& Commerce, vol. 3, no. 2, pp. 33-39.

Farrell, D. Laboissière, M. A. Rosenfeld, J. (2006),' Sizing the Emerging Global Labor Market: Rational Behavior from Both Companies and Countries Can Help It Work More Efficiently', The Academy of Management Perspectives, Volume 20, Number 4, Pages 2334

Furtmueller, E., Wilderom, C. and Tate, M. (2011), 'Managing recruitment and selection in the digital age: e-HRM and resumes', Human Systems Management, Volume 30, Number 4, Pages 243-259.
Jie, S (2005), 'Human resource outsourçing: 1990-2004', Journal of Organisational Transformation \& Social Change, Volume 2, Number 3, Pages 275-296.

Kanter, R.M. (2004), 'The Middle Manager as Innovator', Harvard 'Business Review, Volume 82, Pages 150-161.

Kock, H., Wallo, A., Nilsson, B. and Höglund, C. (2012), 'Outsourcing HR services: the role of human resource intermediaries', European Journal of Training and Development, Volume 36 , Number 8, Pages $772-790$.

Liang-Hung, L. (2011), 'Electronic human resource management and organizational innovation: the roles of information technology and virtual organizational structure', International Journal of Human Resource Management, Volume 22, Number 2, Pages 235-257.

Mahmud, K., Billah, M.M. and Chowdhury, S.M.R. (2012), 'Human resource outsourcing: a study on telecommunication sector in Bangladesh', International Journal of Business and Management, Volume 7, Number 10, Pages 74-84.

Parry, E 2011, 'An examination of e-HRM as a means to increase the value of the HR function', International Journal of Human Resource Management, Volume 22, Number 5, Pages 1146-1162.

Parry, E \& Tyson, S 2011, 'Desired goals and actual outcomes of e-HRM', Human Resource Management Journal, Volume 21, Number 3, Pages 335-354.

Peter H., Cathy S., Ross D. and Amanda P. (2012), ' Contemporary Issues and Challenges in HRM '(2nd)', Prahran, VIC, Australia: Tilde University press, ISBN: 9780734611093 / 9780-7346-1109-3

HR Focus. (2010), 'Recruiting and Marketing AreTop Benefits of Social Media', Volume 87, Issue 1, Pages S1-S4.

Schwartz, Ephraim (2005), 'Security Lessons Learned', InfoWorld, Volume 27, Issue 27.

Cooke, F. L., Shen, J. and McBride, A. (2005), 'Outsourcing HR as a competitive strategy? A literature review and an assessment of implications', Human Resource Management, Volume 44, Number 4, Pages 413-432.

Debnath,S., Chandra and Kenji, Y. (2011), 'The Role of Good governance in the knowledgebased economy growth of East Asia- A study on Japan', Newly Industrial Economies, Malaysia and China, Pages 1-24.

Pickard, J. Í. (2000), 'Study casts doubt on boom in outsourcing', People Management, Pages 16. 